\title{
The Use of Thermal Water Vapor Arc Plasma as an Oily Soil Remediation Technique ${ }^{+}$
}

\author{
Dovilè Gimžauskaitè 1,*, Andrius Tamošiūnas 1, Simona Tučkutė 2, Vilma Snapkauskienė 1, \\ Mindaugas Aikas ${ }^{1}$ and Rolandas Uscila ${ }^{1}$ \\ 1 Lithuanian Energy Institute, Plasma Processing Laboratory, Breslaujos st. 3, Kaunas LT-44403, Lithuania; \\ Andrius.Tamosiunas@lei.lt (A.T.); Vilma.Snapkauskiene@lei.lt (V.S.); Mindaugas.Aikas@lei.lt (M.A.); \\ Rolandas.Uscila@lei.lt (R.U.) \\ 2 Lithuanian Energy Institute, Center for Hydrogen Energy Technologies, Breslaujos st. 3, Kaunas LT-44403, \\ Lithuania; Simona.Tuckute@lei.lt \\ * Correspondence: Dovile.Gimzauskaite@lei.lt; Tel.: +370-37-401-999 \\ + Presented at the 2nd International Research Conference on Sustainable Energy, Engineering, Materials and \\ Environment (IRCSEEME), Mieres, Spain, 25-27 July 2018.
}

Published: 1 November 2018

\begin{abstract}
Contaminated soil remediation with plasma is a new and little explored method. Thus, the aim of this study was to investigate thermal water vapor arc plasma suitability to remediate soil polluted by petroleum hydrocarbons (diesel). Also, the impact of different initial pollutant concentrations was investigated. Scanning electron microscopy (SEM) data showed that soil surface morphology depends on diesel fuel concentration in the soil. Results obtained with energy dispersive X-ray spectroscopy (EDS) indicated that carbon content in soil decreased after the treatment process and became similar to the carbon content in the clean soil. Furthermore, the measurements taken with gas analyzer revealed the thermal water vapor arc plasma suitability to remediate contaminated soil as well as generate by-product-synthesis gas $\left(\mathrm{H}_{2}+\mathrm{CO}\right)$. It was observed that the amount of generated synthesis gas depends on the soil moisture content.
\end{abstract}

Keywords: soil remediation; petroleum hydrocarbons; synthesis gas; water vapor; thermal arc plasma

\section{Introduction}

Soil contamination by petroleum-based fuels is considered as a serious environmental problem. Petroleum hydrocarbons (diesel, heavy oil, etc.) strongly adsorbs and remains in the soil, consequently it is difficult to remove them from the soil [1]. Therefore, the treatment of these pollutants is required. Although numerous soil remediation methods based on biological, physical, chemical, physicochemical and thermal processes exist [2], all of them have disadvantages due to long treatment periods of time, usage of chemical reagents, generation of second pollutants, and they cannot meet the requirements of high-efficient and rapid remediation [3]. Meanwhile, plasma technologies did not suffer from these drawbacks. Nevertheless, contaminated soil remediation with plasma is a new and little explored method. Therefore, the aim of this experimental research was to investigate thermal water vapor arc plasma suitability to remediate soil polluted by diesel fuel. The impact of different initial pollutant concentrations was investigated.

\section{Methodology}

Dry soil samples were artificially contaminated by diesel fuel at three different concentrations: $80 \mathrm{~g} / \mathrm{kg}, 120 \mathrm{~g} / \mathrm{kg}$ and $160 \mathrm{~g} / \mathrm{kg}$, respectively. The remediation of the polluted soil with water vapor plasma was performed under atmospheric pressure for $\sim 30 \mathrm{~min}$. The power of the plasma torch was 
$56 \mathrm{~kW}$ at the water vapor flow rate of $3.8 \mathrm{~g} / \mathrm{s}$, current $(160 \mathrm{~A})$ and voltage $(350 \mathrm{~V})$. The operating mean temperature of plasma stream was $\sim 2800 \mathrm{~K}$. A simplified scheme of the plasma-chemical reactor used for the remediation of the soil polluted by diesel fuel is shown in Figure 1.

Soil characterization was done before and after remediation with water vapor plasma. The surface morphology and the elemental composition of the clean, polluted and plasma treated soil were investigated by the scanning electron microscopy (SEM, Hitachi S-3400N) and the energy dispersive X-ray spectroscopy (EDX, Bruker Quad 0540), respectively. Multi-component gas analyser (MRU SWG 300) was used to determine gas concentrations which were produced during the interaction between polluted soil and water vapor plasma stream.

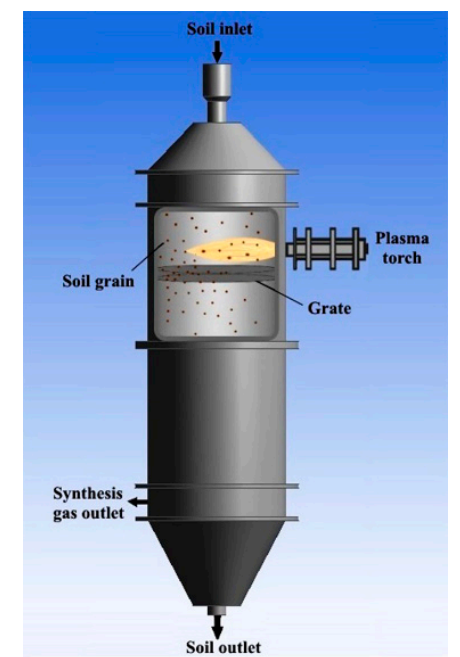

Figure 1. A simplified scheme of plasma-chemical reactor.

\section{Results and Discussion}

Surface morphology of clean soil, soil polluted with different diesel fuel concentrations $(80 \mathrm{~g} / \mathrm{kg}$, $120 \mathrm{~g} / \mathrm{kg}$ and $160 \mathrm{~g} / \mathrm{kg}$, respectively) and soil remediated with water vapor plasma was investigated by the scanning electron microscopy (SEM) (Figure 2). Clean soil (Figure 2a) has small irregularlyshaped agglomerates. SEM images of polluted soil (Figure $2 b-d$ ) show surface changes, soil consists of larger irregularly-shaped agglomerates. The moisture of soil increases with increasing concentration of the pollutant and this causes the growing adhesion of soil particles into larger agglomerates. After soil remediation with water vapor plasma the soil particles (Figure 2e-g) became smaller and similar to clean soil particles (Figure 2a).

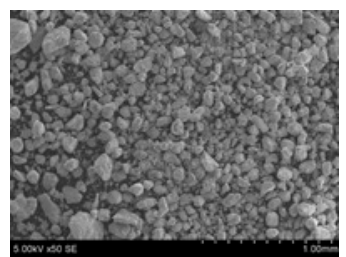

(a)

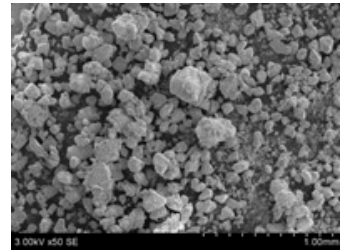

(b)

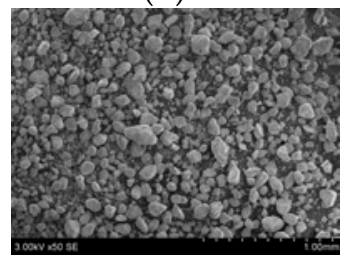

(e)

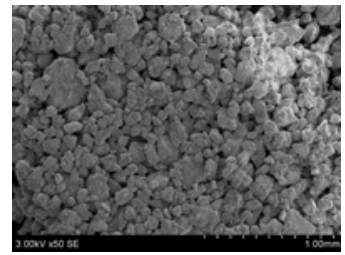

(c)

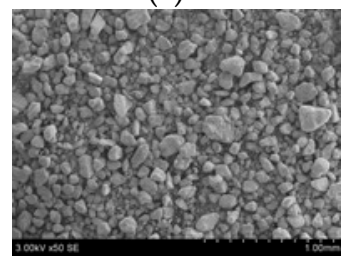

(f)

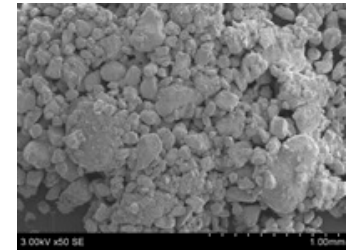

(d)

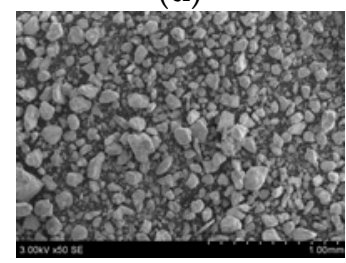

(g)

Figure 2. SEM images of soil surface: (a) Clean soil; (b) Soil polluted with diesel (80 g/kg); (c) Soil polluted with diesel (120 g/kg); (d) Soil polluted with diesel $(160 \mathrm{~g} / \mathrm{kg})$; (e) Polluted $(80 \mathrm{~g} / \mathrm{kg})$ soil after remediation; (f) Polluted (120 g/kg) soil after remediation; (g) Polluted (160 g/kg) soil after remediation. 
Elemental composition of clean soil, soil polluted with different diesel concentrations $(80 \mathrm{~g} / \mathrm{kg}$, $120 \mathrm{~g} / \mathrm{kg}$ and $160 \mathrm{~g} / \mathrm{kg}$, respectively) and soil treated with water vapor plasma are summarized in Table 1. Elemental analysis by the energy dispersive X-ray spectroscopy (EDS) shows that increasing concentration of diesel (from $80 \mathrm{~g} / \mathrm{kg}$ to $160 \mathrm{~g} / \mathrm{kg}$, respectively), raises carbon concentration from $\sim 5 \%$ to $\sim 10.4 \%, \sim 15.6 \%$ and $\sim 20 \%$, respectively. Moreover, after soil remediation with water vapor plasma carbon concentration decreased to $\sim 4 \%, \sim 2.2 \%$ and $\sim 3.5 \%$, respectively, and the concentration has become close to the initial clean soil concentration $(\sim 5 \%)$. Furthermore, during the soil remediation process the concentrations of soil minerals $(\mathrm{K}, \mathrm{Ca}, \mathrm{Mg}, \mathrm{Al}, \mathrm{Fe}, \mathrm{Na}, \mathrm{Ti})$ changed insignificantly. According to Snellings et al. [4] (p. 234) most of the minerals that are presented in the burned sediments not volatilize. Thus some of minerals remain unchanged, some became amorphous or recrystallize to form secondary minerals.

Table 1. Elemental composition of clean, polluted and treated soil.

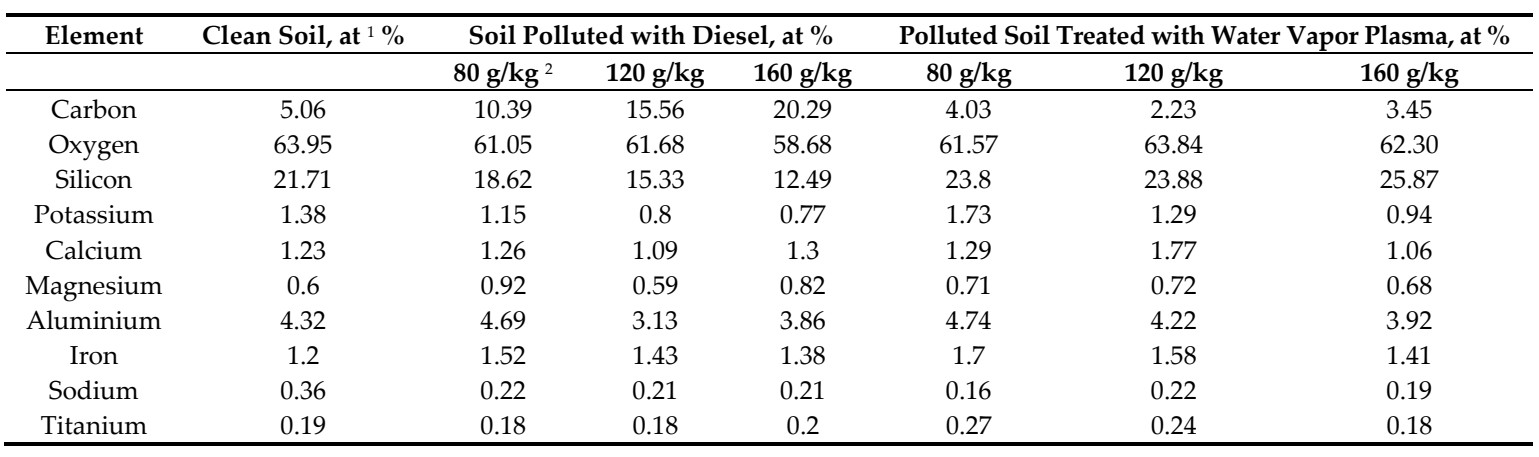

${ }^{1}$ Atomic concentration of element, \%; ${ }^{2}$ Diesel concentration in the soil, $\mathrm{g} / \mathrm{kg}$.

Changes of gas concentrations generated during oily soil treatment process are shown in Figure 3. Significant decrease in oxygen (from $\sim 21 \%$ to $1.69-0.75 \%$ ) and generation of the synthesis gas $\left(\mathrm{H}_{2}\right.$ $+\mathrm{CO}$ ) were recorded. Thus, up to $\sim 36.7 \%, \sim 44.5 \%, \sim 27.5 \%$ of synthesis gas and up to $\sim 34.9 \%, \sim 15.9 \%$, $\sim 15.3 \%$ of $\mathrm{CO}_{2}$ were measured then soil was polluted with $80 \mathrm{~g} / \mathrm{kg}, 120 \mathrm{~g} / \mathrm{kg}, 160 \mathrm{~g} / \mathrm{kg}$ of diesel fuel, respectively. Hence, diesel fuel was transformed to gaseous compounds such as $\mathrm{CO}, \mathrm{H}_{2}$ and $\mathrm{CO}_{2}$ during interaction between polluted soil and water vapor plasma stream. Furthermore, negligible amounts of $\mathrm{NO}(\sim 0.55 \%), \mathrm{NO}_{2}(\sim 0.07), \mathrm{SO}_{2}(\sim 0.05)$ and $\mathrm{C}_{3} \mathrm{H}_{8}(0.13-0.21 \%)$ were obtained in all cases.

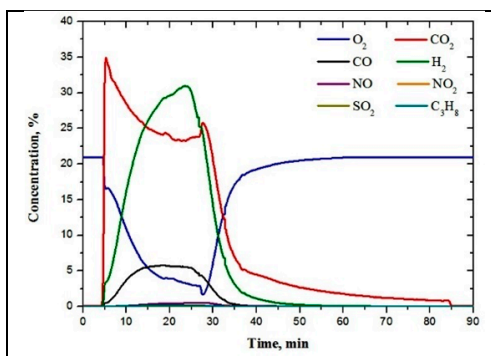

(a)

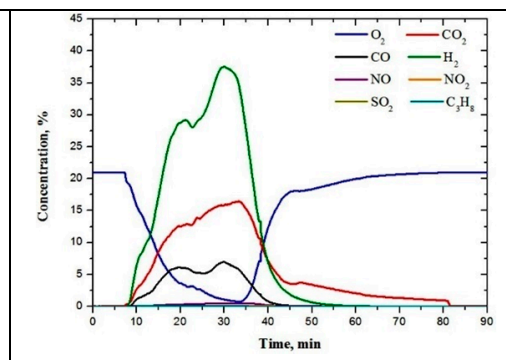

(b)

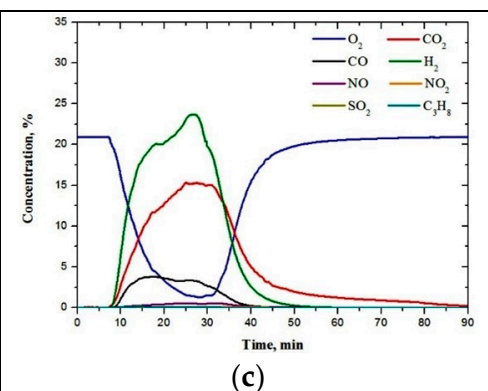

(c)

Figure 3. Gas concentrations extracted during remediation process: (a) Soil polluted with diesel $(80 \mathrm{~g} / \mathrm{kg}) ;($ b) Soil polluted with diesel (120 g/kg); (c) Soil polluted with diesel (160 g/kg).

The synthesis gas generation dependence on the concentration of the diesel fuel in the soil is presented in Figure 4. As the concentration of diesel fuel increased from $80 \mathrm{~g} / \mathrm{kg}$ to $120 \mathrm{~g} / \mathrm{kg}$, the generation of synthesis gas $\left(\mathrm{H}_{2}+\mathrm{CO}\right)$ increased from $\sim 36.7 \%$ to $\sim 44.5 \%$, respectively. However, a decrease in the formation of synthesis gas is observed at the highest concentration of the diesel fuel $(160 \mathrm{~g} / \mathrm{kg})$. Consequently, the amount of moisture in contaminated soil affects the decontamination of pollutants. Low moisture content in the soil increases the degradation of pollutants as well as generation of synthesis gas. Nevertheless, a positive effect of moisture is observed up to a certain amount of moisture. Similar effect of the moisture in the soil was also observed by other researchers [5]. 


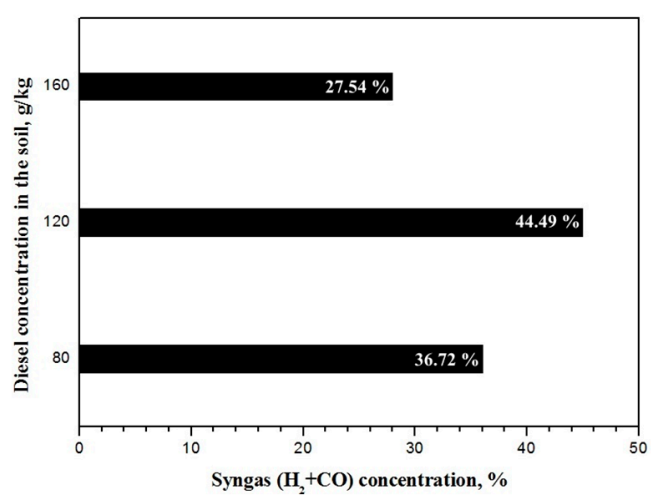

Figure 4. The dependence of synthesis gas generation on diesel concentration in the soil.

\section{Conclusions}

Scanning electron microscopy (SEM) images showed that the soil surface morphology depended on diesel fuel concentration in the soil. Increasing concentration of the pollutant caused the growing adhesion of soil particles into larger agglomerates. The soil particles became similar to clean soil particles after remediation with water vapor plasma. Analysis performed by the energy dispersive X-ray spectroscopy (EDS) indicated that carbon concentration in the soil after treatment with water vapor plasma has become similar to the carbon concentration in the clean soil. Measurements taken with gas analyzer showed that diesel fuel was transformed to $\mathrm{CO}, \mathrm{H}_{2}$ and $\mathrm{CO}_{2}$ during interaction between contaminated soil and water vapor plasma. Furthermore, the amount of generated synthesis gas $\left(\mathrm{H}_{2}+\mathrm{CO}\right)$ depended on the soil moisture content.

Author Contributions: D.G. and A.T. conceived and performed the experiments, analyzed the data and wrote the paper. S.T. performed analysis with analysis tools (SEM, EDS) and analyzed data, V.S., M.A. and R.U. designed and performed the experiments.

Acknowledgments: This work was supported by the Public Agency "Soil remediation technologies", project No. 17-34/15-1775.17.18.

Conflicts of Interest: The authors declare no conflict of interest.

\section{References}

1. Bocos, E.; Fernández-Costas, C.; Pazos, M.; Sanromán, M.A. Removal of PAHs and pesticides from polluted soils by enhanced electrokinetic-Fenton treatment. Chemosphere 2015, 125, 168-174.

2. Lim, M.W.; Lau, E.V.; Poh, P.E. A comprehensive guide of remediation technologies for oil contaminated soil-Present works and future directions. Mar. Pollut. Bull. 2016, 109, 14-45.

3. Wang, T.; Qu, G.; Sun, Q.; Liang, D.; Hu, S. Formation and roles of hydrogen peroxide during soil remediation by direct multi-channel pulsed corona discharge in soil. Sep. Purif. Technol. 2015, 147, 17-23.

4. Snellings, R.; Mertens, G.; Elsen, J. Supplementary Cementitious Materials. Rev. Mineral. Geochem. 2012, 74, 211-278, doi:10.2138/rmg.2012.74.6.

5. Li, R.; Liu, Y.; Mu, R.; Cheng, W.; Ognier, S. Evaluation of pulsed corona discharge plasma for treatment of petroleum-contaminated soil. Environ. Sci. Pollut. Res. 2017, 24, 1450-1458, doi:10.1007/s11356-016-7929-x.

(C) 2018 by the authors. Licensee MDPI, Basel, Switzerland. This article is an open access article distributed under the terms and conditions of the Creative Commons Attribution (CC BY) license (http://creativecommons.org/licenses/by/4.0/). 